\title{
WIRELESS CAPACITIVE PRESSURE SENSOR WITH DIRECTIONAL RF CHIP ANTENNA FOR HIGH TEMPERATURE ENVIRONMENTS
}

\author{
M.C. Scardelletti ${ }^{1}$, J.L. Jordan ${ }^{1}$, G.E. Ponchak ${ }^{1}$, and C. A. Zorman ${ }^{2}$ \\ ${ }^{1}$ NASA Glenn Research Center, Cleveland, OH, USA \\ ${ }^{2}$ Case Western Reserve University, Cleveland, OH, USA
}

\begin{abstract}
This paper presents the design, fabrication and characterization of a wireless capacitive pressure sensor with directional RF chip antenna that is envisioned for the health monitoring of aircraft engines operating in harsh environments. The sensing system is characterized from room temperature $\left(25^{\circ} \mathrm{C}\right)$ to $300^{\circ} \mathrm{C}$ for a pressure range from 0 to $100 \mathrm{psi}$. The wireless pressure system consists of a Clapp-type oscillator design with a capacitive MEMS pressure sensor located in the LC-tank circuit of the oscillator. Therefore, as the pressure of the aircraft engine changes, so does the output resonant frequency of the sensing system. A chip antenna is integrated to transmit the system output to a receive antenna $10 \mathrm{~m}$ away.

The design frequency of the wireless pressure sensor is $127 \mathrm{MHz}$ and a $2 \%$ increase in resonant frequency over the temperature range of 25 to $300{ }^{\circ} \mathrm{C}$ from 0 to $100 \mathrm{psi}$ is observed. The phase noise is less than $-30 \mathrm{dBc} / \mathrm{Hz}$ at the $1 \mathrm{kHz}$ offset and decreases to less than $-80 \mathrm{dBc} / \mathrm{Hz}$ at $10 \mathrm{kHz}$ over the entire temperature range. The RF radiation patterns for two cuts of the wireless system have been measured and show that the system is highly directional and the MEMS pressure sensor is extremely linear from 0 to $100 \mathrm{psi}$.
\end{abstract}

\section{KEYWORDS}

Wireless capacitive pressure sensor system, MEMS, chip antenna, passive and active components, high temperature applications, health monitoring.

\section{INTRODUCTION}

Sensing systems for health monitoring in harsh environments, specifically high temperatures, are of extreme importance and are highly sought for many applications from the oil and gas industry to monitoring the performance of aerospace systems. Currently, the largest user of high-temperature sensing electronics is the downhole oil and gas industry. In the past, drilling operations were at maximum temperatures of $150^{\circ} \mathrm{C}$ to $175^{\circ} \mathrm{C}$, but declining reserves of easily accessible natural resources, coupled with the advances in technology, have motivated the industry to drill deeper, and as a result, the electronics must operate as high as $300^{\circ} \mathrm{C}$ [1]. The automotive industry is another field where high temperature sensor electronics are widely used. The need to locate sensors, signal conditioning and control electronics closer to the heat sources will be an essential requirement [2]. For example, cylinder pressure temperatures are monitored up to $300^{\circ} \mathrm{C}$, and exhaust sensing can be as high as $850^{\circ} \mathrm{C}$ [3]. Additionally, in the aerospace industry, aircraft engines that use intelligent controls and health monitoring require a variety of sensors [4]. Many of the sensors operate at temperatures at and above $500^{\circ} \mathrm{C}$, requiring electronics that can function at these temperatures to assure essential health monitoring $[5,6]$. Combining health monitoring in harsh environments with real-time wireless transmission of diagnostic data to a remote receiver greatly enhances the sensing system functionality and importance [7]. Although efforts in this area have been made, they often used large thin film spiral inductors as the radiating element $[8,9]$. However, large inductors are very sensitive to changes in environmental conditions, including a shift in the output frequency if the inductor is placed near a metallic surface. In addition, the large spiral inductor greatly increases the overall size of the sensing system.

In this paper, the development of a wireless capacitive MEMS pressure sensor with integrated directional chip antenna designed for high temperature applications is described. To the best of our knowledge, this is the first effort to integrate a chip antenna with a sensing system for harsh environment applications. The directional antenna allows for maximum power transfer to the receiver. A matching network was added to the input of the chip antenna to shift its resonant frequency to that of the oscillator/pressure sensor. The wireless sensor system on chip performance as a function of temperature is demonstrated from room temperature $\left(25^{\circ} \mathrm{C}\right)$ to $300^{\circ} \mathrm{C}$ for a pressure range of 0 to $100 \mathrm{psi}$. Additionally, two cuts of the radiation pattern, vertical and horizontal, of the wireless system are presented and show highly directional capabilities.

\section{PRESSURE SENSOR DESIGN}

The capacitive micro-electromechanical systems (MEMS) pressure sensor was developed by Sporian Microsystems and is shown in Fig. 1. One electrode of the capacitive sensor is fabricated on the deflecting chamber membrane which forms a sealed cavity and the second electrode is on the fixed silicon carbide nitride $(\mathrm{SiCN})$ substrate. The sealed cavity is flip-chip bonded onto a SiCN substrate with gold $(\mathrm{Au})$ contacts so the tow electrodes form a parallel plate capacitor. The Sporian Microsystem pressure sensor was characterized with an Agilent B1500A Semiconductor 
Device Analyzer (SDA) and a high temperature/pressure chamber (HTPC), shown in Fig. 2. The SDA was calibrated to the leads of the pressure sensor inside the HTPC at room temperature to remove the effects of the chamber and cabling. The pressure sensor capacitance was measured at $1 \mathrm{MHz}$ from 0 to $100 \mathrm{psi}$ at $25^{\circ} \mathrm{C}$, and the results are shown in Fig. 3. The pressure sensor was measured twice to demonstrate reliability. The capacitance is $5.15 \mathrm{pF}$ at $0 \mathrm{psi}$ and decreases to $4.41 \mathrm{pF}$ at $100 \mathrm{psi}$, resulting in a $\Delta \mathrm{C}$ of $0.74 \mathrm{pF}$.

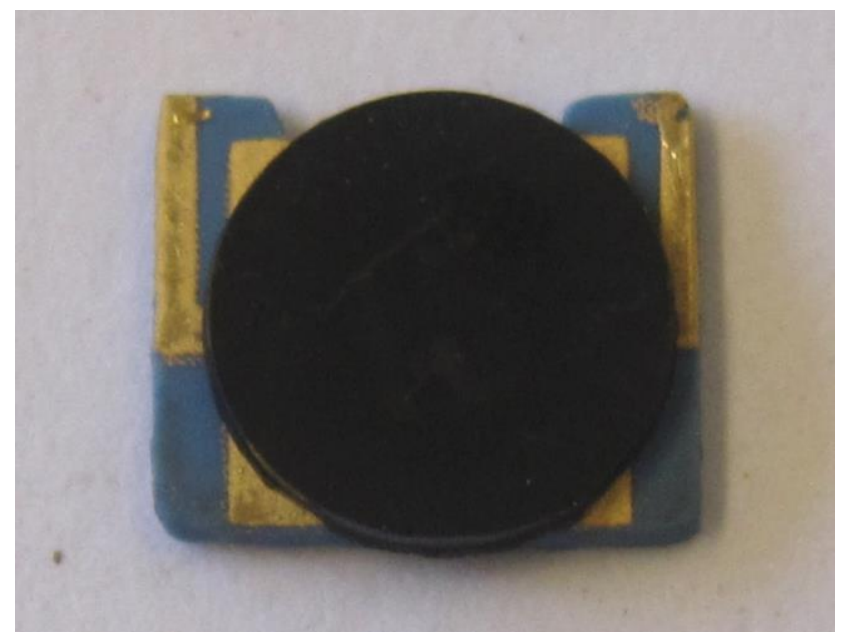

Figure 1: Sporian Microsystem capacitive pressure sensor.
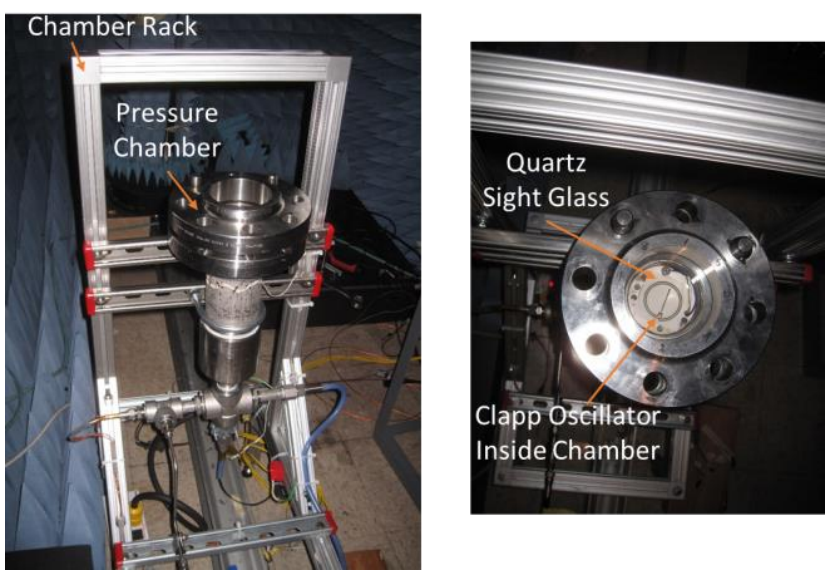

Figure 2. High temperature pressure chamber.

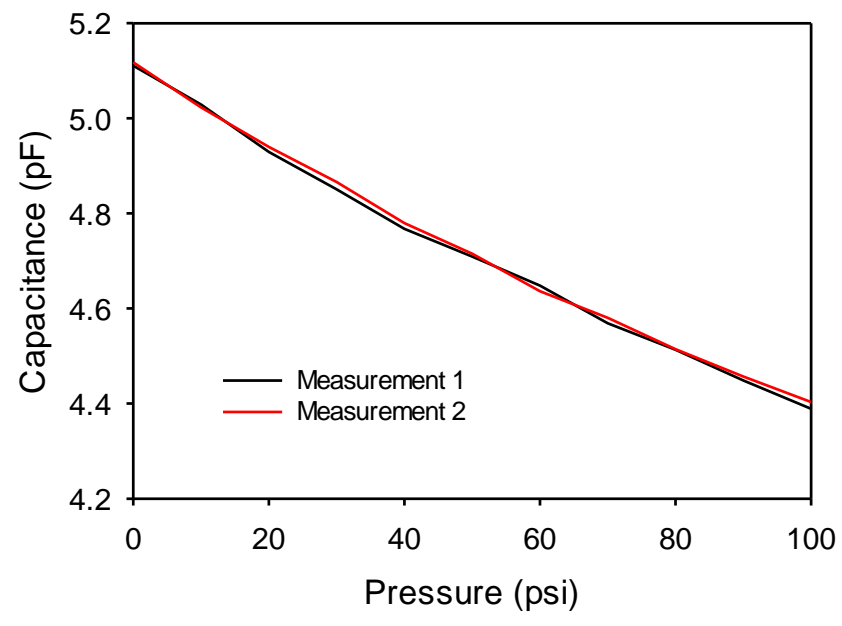

Figure 3: Capacitance versus pressure at $25^{\circ} \mathrm{C}$.

\section{OSCILLATOR WITH PRESSURE SENSOR}

A circuit schematic of the Clapp-type oscillator with an integrated capacitive pressure sensor is shown Fig. 4. The resonant frequency of the oscillator greatly depends on the values of the inductor, $\mathrm{L}_{\mathrm{T}}$, and the pressure sensor, $\mathrm{C}_{\mathrm{T}}$. As the pressure increases, the capacitance of the pressure sensor decreases, causing the resonate frequency of the sensing system to increase. More information on the design methodology for this oscillator can be found in [10].

The sensing system was fabricated on an alumina CoorsTek Superstrate 996 with a dielectric constant of 9.9 and a substrate thickness of $500 \mu \mathrm{m}$. The metallization consists of a $\mathrm{Ti} / \mathrm{Au}(0.15 / 1.5 \mu \mathrm{m})$ layer, which was deposited using an E-beam evaporator. Finally, gold wire bonds were used to make electrical connections between components and pads.

A Cree CRF24010D SiC MESFET is the active device used in this system. The values for $\mathrm{L}_{\mathrm{T}}, \mathrm{C}_{1}$, and $\mathrm{C}_{2}$ are $390 \mathrm{nH}, 13 \mathrm{pF}$, and $40 \mathrm{pF}$, respectively. $\mathrm{L}_{\mathrm{T}}$ is a Johanson $\mathrm{RF}$ wire wound $390 \mathrm{nH}$ chip inductor. The inductor was tested from room temperature to $400^{\circ} \mathrm{C}$ and showed less than a $2 \%$ decrease in inductance up to $350^{\circ} \mathrm{C}$, after which the inductance dropped by $8 \%$ at $400^{\circ} \mathrm{C}$. It should be noted that the inductors were left to cool down to room temperature and re-measured the following day and found to retain their original inductance value of $390 \mathrm{nH}$, which indicates that the inductors were not permanently modified by the high temperature measurements. The chip capacitors, $\mathrm{C}_{1}$ and $\mathrm{C}_{2}$, from Compex type C-50, consist of a thin titanate dielectric material, with dielectric constant of 40 and thickness of $76.4 \mu \mathrm{m}$ with gold metallization on both sides. $C_{1}$ is a single chip capacitor with a value $13 \mathrm{pF}$ and $\mathrm{C}_{2}$ is a single chip capacitor of $40 \mathrm{pF}$. Similar to the chip 
inductors, the Compex chip capacitors were also characterized separately up to $500^{\circ} \mathrm{C}$ and show less than $1 \%$ variation in capacitance up $400^{\circ} \mathrm{C}$, after which the capacitance falls off by $5 \%$ at $500^{\circ} \mathrm{C} . \mathrm{C}_{\mathrm{T}}$ is the Sporian pressure sensor that was described previously. $\mathrm{L}_{\mathrm{d}}, \mathrm{C}_{\mathrm{d}}$, and $\mathrm{R}_{\mathrm{g}}$ are the DC bias circuits and are off chip and are left at room temperature. Their values are $2.5 \mathrm{mH}, 1.5 \mu \mathrm{F}$, and 5 $\mathrm{k} \Omega$, respectively. The active pressure sensor system was designed to operate at $127 \mathrm{MHz}$ and increase to $130 \mathrm{MHz}$ at 0 psi and $100 \mathrm{psi}$, respectively, at room temperature, based on the change in capacitance of the Sporian pressure sensor. Although the design frequency was chosen based on currently available chip capacitors and inductors, it can easily be modified for other design frequencies.

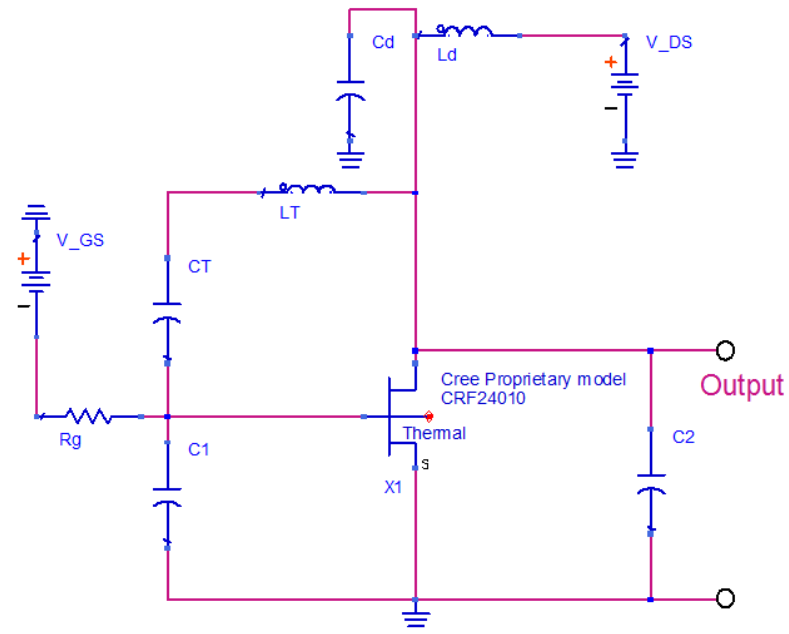

Figure 4. Circuit schematic of oscillator with integrated capacitive pressure sensor.

\section{CHIP ANTENNA}

A Johanson Technology ISM chip antenna (P/N: 0169AT62A0010) was used to transmit the RF output signal from the oscillator with integrated pressure sensor to a receive antenna $10 \mathrm{~m}$ away. The nominal resonant frequency of the chip antenna is $169 \mathrm{MHz}$ when using Johanson's suggested circuit board and matching network at the input of the antenna. However, the resonant frequency of the antenna is highly dependent on several factors, such as antenna placement with respect to a ground plane (if used), matching network, and substrate/circuit board material. In this case, the antenna is epoxied to an alumina substrate with no ground plane. The alumina substrate is chosen due to its ability to withstand high temperatures $[11,12]$. The chip antenna with coplanar waveguide (CPW) feed line and matching network is shown in Fig. 5. The return loss $\left(\mathrm{S}_{11}\right)$ of the chip antenna with and without a matching network, shown in Fig. 6, was characterized with the Agilent E8361C Precision Network
Analyzer (PNA) and ground-signal-ground (GSG) probes to facilitate connection to the CPW feed lines.

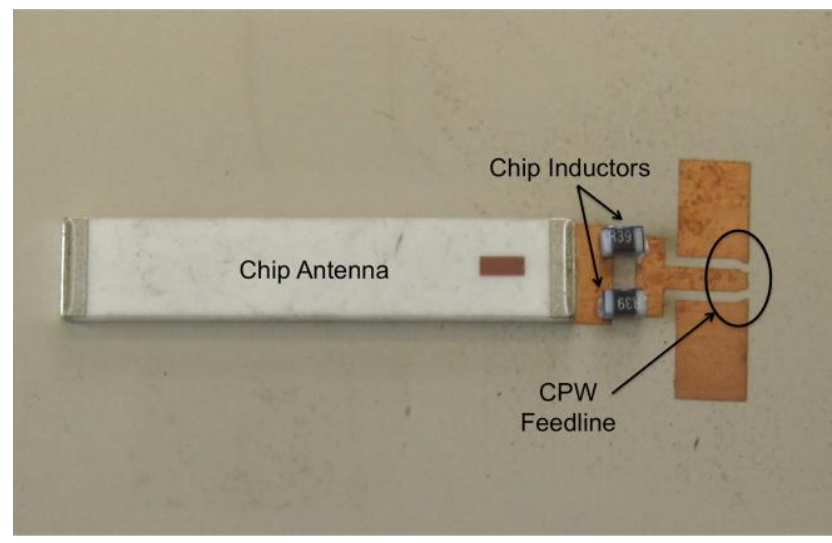

Figure 5. Chip antenna, matching network and CPW feed line.

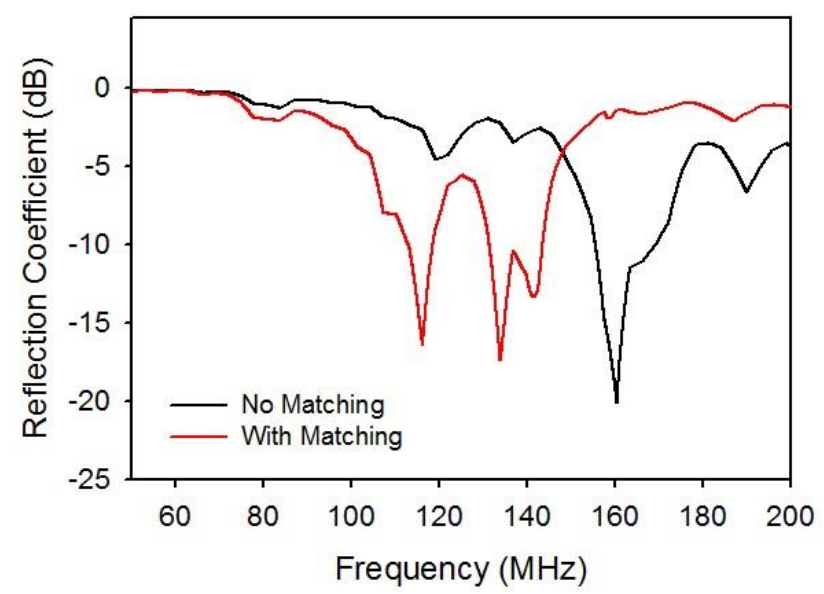

Figure 6. Return Loss of chip antenna with and without matching networks.

Since the return loss of the chip antenna has a resonant frequency of $160 \mathrm{MHz}$, a matching network must be added. The matching network designed for this application must decrease the resonant frequency to that of the original design frequency as well as increase the operational bandwidth to accommodate the change in oscillator/pressure sensor frequency change due to the change in pressure. The matching network consisted of two Johanson $390 \mathrm{nH}$ wire wound chip inductors placed in shunt at the input to the antenna, which results in an equivalent inductance of $195 \mathrm{nH}$. Accordingly, the reflection coefficient of the chip antenna is at least $-5 \mathrm{~dB}$ over the operational bandwidth of $125 \mathrm{MHz}$ to $145 \mathrm{MHz}$. 


\section{WIRELESS PRESSURE SENSOR}

The chip antenna and matching network were added to the output of the oscillator/pressure sensor via gold wire bonds, as seen in Fig. 7. All components were mounted onto alumina substrates using high temperature silver epoxy from Cotronics. The pressure sensor is $15 \mathrm{~mm} \times 5 \mathrm{~mm}$, the oscillator is $7 \mathrm{~mm} \times 7 \mathrm{~mm}$, and the chip inductor is $25 \mathrm{~mm}$ x $5 \mathrm{~mm}$, which, if optimized, can be realized in a footprint of approximately $250 \mathrm{~mm}^{2}$. When compared to [8], with an approximate area of $2,580 \mathrm{~mm}^{2}$, the percentage of area reduction is nearly $90 \%$. For a room temperature, unpressurized test of the system, the sensor was mounted on a styrofoam block and placed on a rotary stage. The test was performed in a typical laboratory environment with lab benches and cabinets that acted as reflectors. The signal was transmitted to a Pixel broadband loop antenna over a distance of $10 \mathrm{~m}$. A horizontal and vertical cut of the radiation patterns for the wireless pressure sensing system are presented in Fig. 8 and show the system to be directional with a maximum power of $-23 \mathrm{dBm}$ at $25^{\circ} \mathrm{C}$.

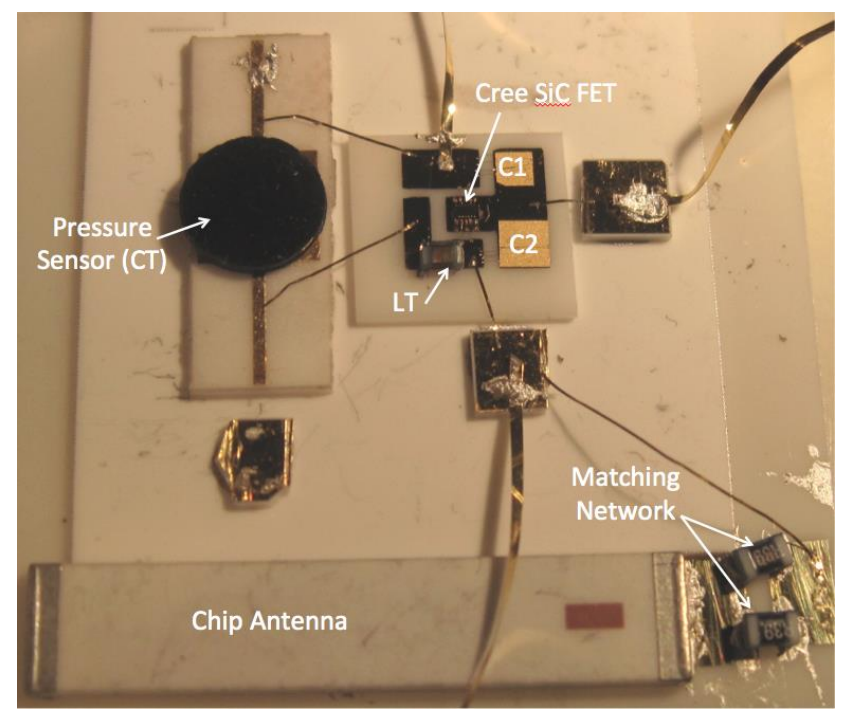

Figure. 7. Compact wireless pressure sensor with directional antenna.

The high temperature/pressure chamber, shown in Fig. 2, developed at NASA Glenn Research Center, was used to heat and pressurize the wireless pressure sensor up to $300^{\circ} \mathrm{C}$ and $100 \mathrm{psi}$, respectively. The chamber was fitted with feed-throughs so biasing can be applied and the temperature can be monitored at several different locations throughout the chamber. Because the pressure chamber is metal with a small glass window, far field antenna measurements could not be performed. Instead, a dipole antenna was used as the receive antenna $1 \mathrm{~m}$ above the glass window.

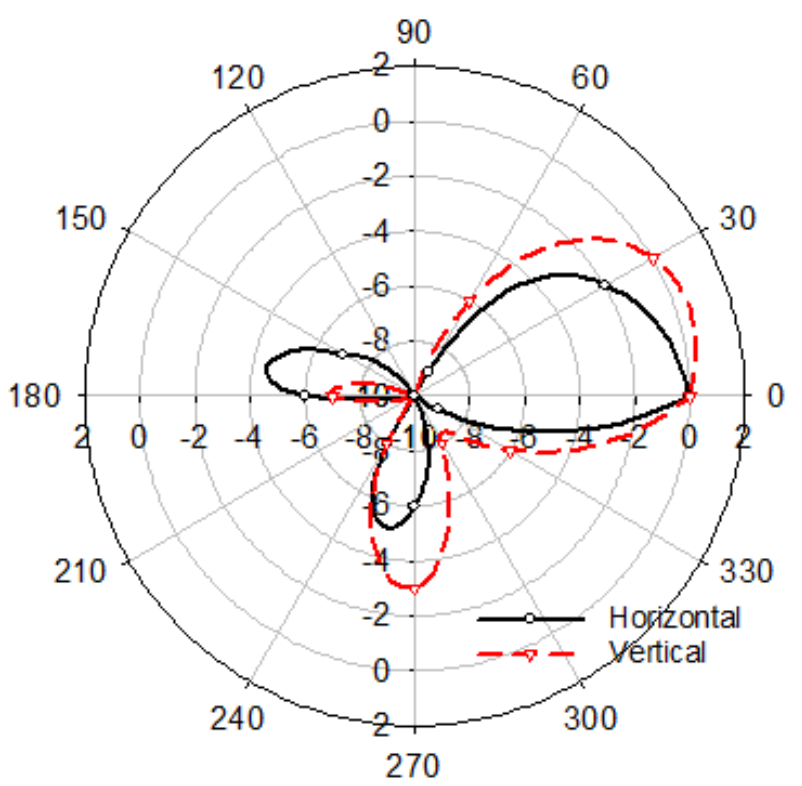

Figure 8. Horizontal and vertical radiation patterns of wireless pressure sensor.

The wireless pressure sensing system was characterized from 25 to $300^{\circ} \mathrm{C}$ for a pressure range of 0 to $100 \mathrm{psi}$, in steps of $10 \mathrm{psi}$, with an Agilent E4440A Series Spectrum Analyzer serving as the receiver. The results are shown in Fig. 9. The output frequency with respect to temperature, over the entire pressure range is linear. The sensitivity of the sensor $(\Delta \mathrm{f} / \Delta \mathrm{P} \mathrm{MHz} / \mathrm{psi})$ is essentially independent of temperature, with values of $2.5,2.6,2.8$ and $2.8 \%$ for $25,100,200$, and $300^{\circ} \mathrm{C}$, respectively.

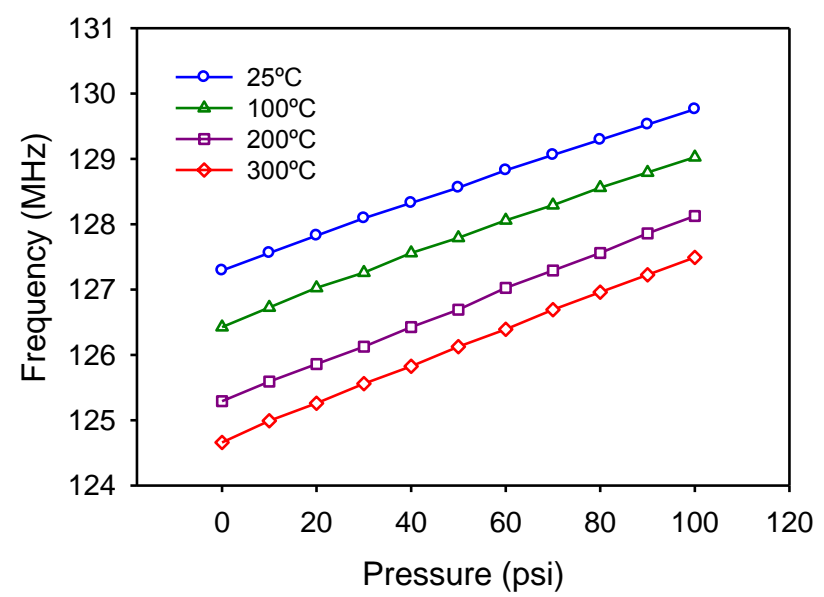

Figure 9. Wireless pressure sensor frequency vs. pressure at $25,100,200$, and $300^{\circ} \mathrm{C}$. 
The power output vs. frequency was recorded at $300^{\circ} \mathrm{C}$ for pressures of 0, 50 and 100 psi and is shown in Fig. 10. The power increases slightly and shifts by approximately $2.5 \mathrm{MHz}$ as a function of pressure. The phase noise of the wireless pressure sensor is shown in Fig. 11 at 0 psi for temperatures of $25,100,200$, and $300^{\circ} \mathrm{C}$. The data show that the $1 \mathrm{kHz}$ offset is below $-30 \mathrm{dBc} / \mathrm{Hz}$ and the $10 \mathrm{kHz}$ offset is below $-80 \mathrm{dBc} / \mathrm{Hz}$. The phase noise slope is -20 $\mathrm{dBc} /$ decade above $10 \mathrm{kHz}$. The two spurs evident at $2 \mathrm{kHz}$ are likely due to the heater power supply fluctuating to maintain temperature.

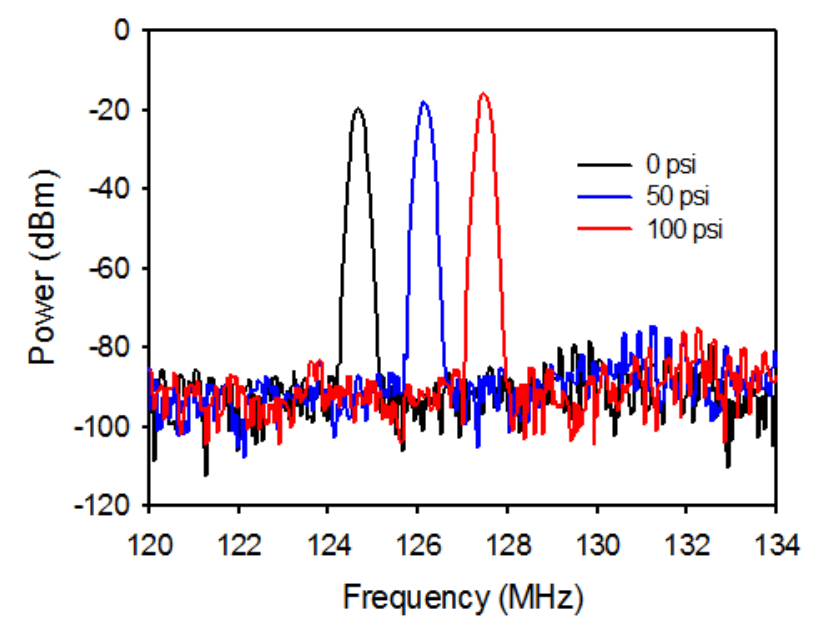

Figure 10 . Output power vs. frequency at $300^{\circ} \mathrm{C}$ for 0,50 and 100 psi.

Phase Noise

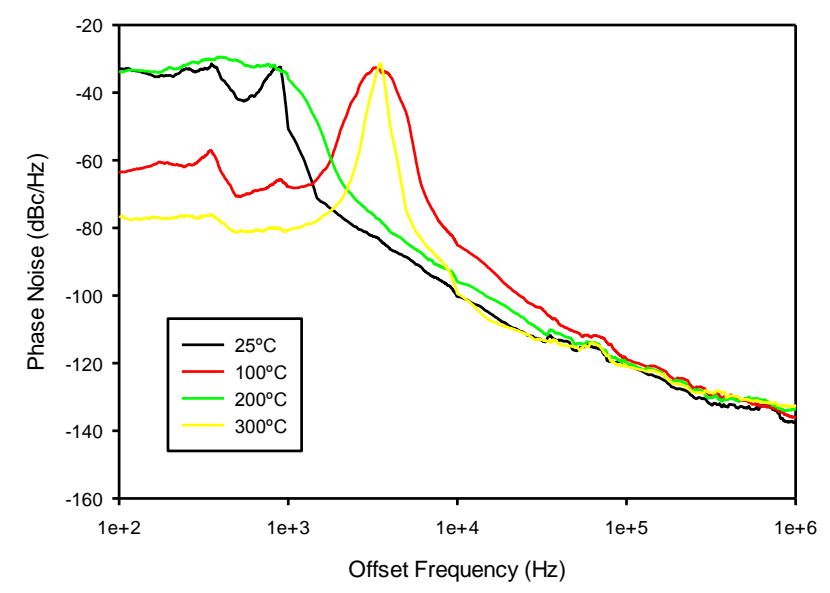

Figure 11. Phase noise of the wireless pressure sensor.

\section{CONCLUSION}

The development of a compact wireless pressure sensor with directional chip antenna for use in high temperature applications has been presented. The wireless system has an extremely linear response over the pressure and temperature ranges of 0 to $100 \mathrm{psi}$ and 25 to $300^{\circ} \mathrm{C}$, respectively. Furthermore, the phase noise of the wireless system is $-30 \mathrm{dBc} / \mathrm{Hz}$ at the $1 \mathrm{kHz}$ offset and goes down to $-80 \mathrm{dBc} / \mathrm{Hz}$ at the $10 \mathrm{kHz}$ offset frequency, indicating the oscillator has good operation over the entire temperature range. The wireless system utilizes a directional chip antenna to create a system that is highly directional over a $10 \mathrm{~m}$ distance. To the best of our knowledge, this is the first successful demonstration of a wireless pressure sensor with an integrated chip antenna operating under high temperature conditions.

\section{ACKNOWLEDGEMENTS}

The authors wish to acknowledge the assistance and support of Elizabeth A. McQuaid for the fabrication of circuits and Nicholas C. Varaljay and Roger D. Meredith for the high temperature/pressure chamber assembly.

\section{REFERENCES}

[1] B. A. Goldstein, A. J. Hill, A. long, A. R. Budd, F. Holgate and M. Malavazos, "Hot rock geothermal energy plays in Australia," Thirty Fourth Workshop on Geothermal Reservoir Engineering, Stanford Univ., Stanford, CA, Feb 9-11, 2009.

[2] J. Watson and G. Castro, "High-Temperature Electronics Pose Design and Reliability Challenges," Analog Dialogue, Volume 46, April, 2012.

[3] R. Johnson, J. Evans, P. Jacobson, J. Thompson and M. Christopher, "The Changing Automotive Environment: High Temperature Electronics," IEEE Transaction on Electronics Packaging Manufacturing, Volume 27, Number 3, July, 2004. Page(s): 164- 176. Digital Object Identifier: 10.1109/TEPM.2004.843109.

[4] J. S. Litt, D. L. Simons, S. Garg, Ten-Heui Guo, C. Mercer, R. Millar, A. Behbahani, A. Bajwa and D. T. Jensen, "A survey of intelligent control and health management technologies for aircraft propulsion systems," NASA/TM-2005-213622, ARL-TR-3413, May 2005.

[5] A. R. Behbahani, "Need for robust sensors for inherently fail-safe gas turbines engine controls, monitoring and prognostics," AFRL-PR-WP-TP2007-217, Nov. 2006, also in Proc. $200652^{\text {nd }}$ Int. Instruments Sypm.

[6] D. E. Culley, R. Thomas and J. Suas, "Concepts for distributed engine control,” NASA TM 2007-214994, Nov. 2007.

[7] G. Chitnis, T. Maleki, B. Samuels, L. B. Cantor, and B. Ziaie, "A Minimally Invasive Implantable Wireless Pressure Sensor for Continuous IOP Monitoring", IEEE Transactions on Biomedical Engineering, Volume: 60, Issue: 1, Part: 2, 2013. Page(s): 250 - 256.

[8] M. C. Scardelletti, G. E. Ponchak, K. Harsh, J. A. Mackey, R. D. Meredith, C. A. Zorman, G. M. Beheim, F. W. Dynys and G. W. Hunter, "Wireless capacitive pressure sensor operating up to $400^{\circ} \mathrm{C}$ form 0 to 100 psi utilizing power scavenging", IEEE Topical 
Conference on Wireless Sensors and Sensor Networks, Newport Beach, CA, January 19 - 23, 2014. Page(s): $34-36$.

[9] J. Yang, "A high temperature RF wireless pressure sensing system", International Conference on Space and Extreme Environments, Noordwijk, The Netherlands, October $30-31,2014$.

[10]G. E. Ponchak, M. C. Scardelletti, J. L. Jordan, "30 and $90 \mathrm{MHz}$ oscillators operating through 450 and $470^{\circ} \mathrm{C}$ for high temperature wireless sensors," Asian Pacific Microwave Conference, 2010, pages 1027-1030.
[11] M. C. Scardelletti, J. L. Jordan, A. R. Asmus and G. E. Ponchak, "High-Temperature Characterization of Alumina Substrates and Folded Slot Antenna" IEEE Antennas and Propagation Conference, June $10-15$, 2007, Page(s): $3800-3803$.

[12] G. E. Ponchak, J. L. Jordan and M. C. Scardelletti, "High Temperature Characteristics of Coplanar Waveguide on R-Plane Sapphire and Alumina", IEEE Advanced Packaging Transactions, Vol. 32, Issue 1, Feb. 2009, pp. 146 - 151. 